\title{
Intermittent warm blood cardioplegia in the surgical treatment of congenital heart disease: Clinical experience with 1400 cases
}

Yves Durandy, MD, and Sylvie Hulin, MD

From Institut Hospitalier Jacques Cartier, Department of Pediatric Perfusion and Intensive Care, Massy, France.

Received for publication Apr 19, 2006; revisions received Sept 15, 2006; accepted for publication Oct 2, 2006.

Address for reprints: Yves Durandy, MD, Institut Hospitalier Jacques Cartier, Avenue du Noyer Lambert 91300, Massy, France (E-mail: iciprea@icip.org).

J Thorac Cardiovasc Surg 2007;133:241-6

$0022-5223 / \$ 32.00$

Copyright $(C) 2007$ by The American Association for Thoracic Surgery

doi:10.1016/j.jtcvs.2006.10.004
Objective: To analyze our experience with warm blood cardioplegia in pediatric cardiac surgery.

Methods: We used intermittent (every 15 minutes after initial injection) warm blood cardioplegia in the treatment of 1400 patients. Results were retrospectively compared with those of 950 patients treated with cold blood cardioplegia. The following parameters were analyzed: (1) hydric balance of cardioplegic solution; (2) resumption of rhythm after aortic crossclamp removal; (3) duration of mechanical ventilation, intensive care unit stay, and incidence of mortality in 4 selected diagnostic groups: ventricular septal defect, tetralogy of Fallot, atrioventricular septal defect, and transposition of the great arteries. These 4 groups, treated with warm or cold cardioplegia, were comparable with regard to age, weight, crossclamp times, and percent with Down syndrome; (4) troponin level at 12 hours after aortic crossclamping; and (5) duration of intensive care unit stay for the 1400 patients.

Results: Warm versus cold cardioplegia: negligible fluid addition with warm cardioplegia compared with blood loss/prime dilution induced by cold cardioplegia; spontaneous resumption of sinus rhythm in $99 \%$ versus $77 \%$ of patients $(P<.001)$; shorter duration of ventilatory support in each diagnostic group, significant in all cases; smaller increase in troponin in each group $(P<.05)$. Incidence of early death was not different in the 2 groups. For the whole group, duration of the intensive care unit stay was less than 48 hours in $86 \%$ versus $75 \%(P<.001)$.

Conclusion: In our experience, normothermic cardioplegia has not generated any particular inconvenience and its use was contemporary, with improved outcomes.

$\mathrm{T}$ The advantages of warm cardioplegia were demonstrated as early as 1989 by the Toronto group ${ }^{1}$ and confirmed later on. ${ }^{2,3}$ At present, this technique is widely used in adult patients, ${ }^{4-6}$ whereas hypothermic cardioplegia remains the standard method in pediatric patients. ${ }^{7}$ The purpose of this study was to describe our clinical experience with intermittent warm blood cardioplegia (IWBC) in neonates, infants, and young children. The efficacy of this method of cardioplegia was assessed by indirect biologic and clinical criteria.

\section{Patients and Methods}

Since April 2001, we have combined IWBC with normothermic extracorporeal circulation. The consent of the families was obtained in every case for this initial experience. The cardioplegia circuit is similar to that used in adults (Figure 1). Oxygenated blood is taken from the oxygenator (diverted from the origin of the arterial line) and injected into a cardioplegia cannula with an occlusive roller pump. The injection is either in the aortic root or directly in the coronary artery ostium. A potassium-enriched solution is added to the blood by means of an electrical syringe pump. This solution, first used at Broussais Hospital in Paris, is marketed under the name CP1B solution by Pharmacie Centrale des Hôpitaux de Paris, Assistance Publique. It has been used for more than 25 years as a cold crystalloid cardioplegic solution and is composed of $0.8 \mathrm{mmol} / \mathrm{mL}$ potassium, $0.8 \mathrm{mmol} / \mathrm{mL}$ magnesium, $2.45 \mathrm{mmol} / \mathrm{mL}$ chloride, and $0.05 \mathrm{mmol} / \mathrm{mL}$ procaine. 


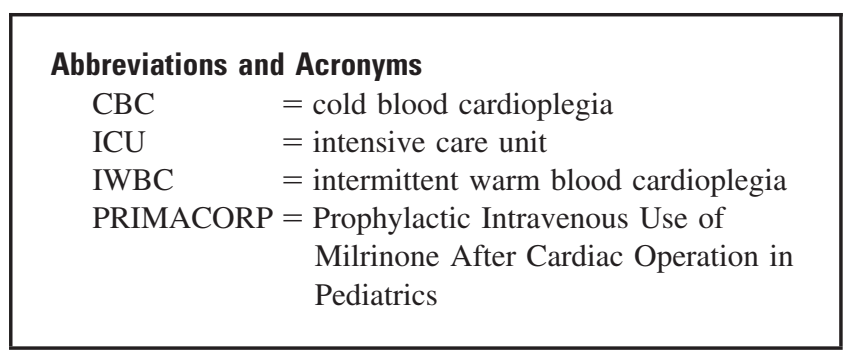

Initial infusion and reinjection rates are calculated according to the patient's body surface area (Table 1); the flow is equal to 1 to 1.5 the physiologic coronary flow (estimated as $5 \%$ of the cardiac output). The initial injection is prolonged for 1 minute after electrical arrest of the heart. Reinjections at two thirds of the initial speed of injection are performed for 1 minute every 15 minutes during aortic crossclamping. The cardioplegic solution is aspirated in the right atrium and returned to the cardiotomy reservoir.

This method has two main implications:

1. The addition of $\mathrm{CP} 1 \mathrm{~B}$ solution to the blood increases the potassium concentration by $13.5 \mathrm{mEq}$ per liter of solution; the final potassium concentration in the solution is around $18 \mathrm{mEq} / \mathrm{L}$

2. The volume of $\mathrm{CP} 1 \mathrm{~B}$ is 60 times less than the volume of blood (Table 1); for example, in a 3-kg baby, an initial injection prolonged for 1.5 minutes is composed of $60 \mathrm{~mL}$ of blood and $1 \mathrm{~mL}$ of $\mathrm{CP} 1 \mathrm{~B}$, and for a $10-\mathrm{kg}$ child, the composition is $150 \mathrm{~mL}$ of blood and $2.5 \mathrm{~mL}$ of $\mathrm{CP} 1 \mathrm{~B}$.

\section{Oxygenator}

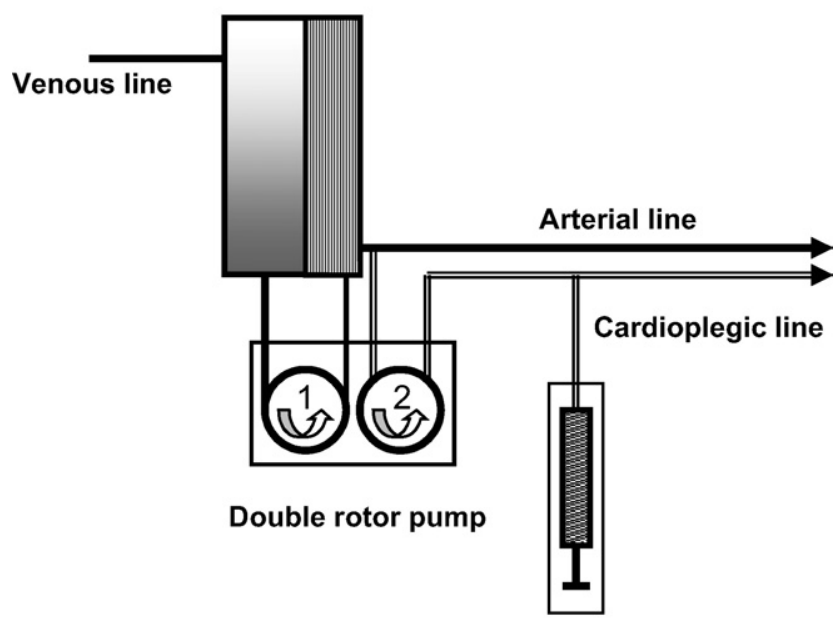

Syringe pump

Figure 1. Cardioplegic circuit. Rotor No. 1 is the arterial pump, performing the total bypass flow. Rotor No. 2 is the cardioplegia pump, diverting the blood component of the warm blood cardioplegic solution. The syringe pump injects the potassiumenriched solution (CP1B solution)
TABLE 1. Nomogram: Flow rates of cardioplegic solution and body surface area

\begin{tabular}{ccc}
\hline BSA $\left(\mathbf{m}^{2}\right)$ & \multicolumn{2}{c}{ Flow rate $(\mathbf{m L} / \mathbf{m i n} \text { and } \mathbf{m L} / \mathbf{h})^{*}$} \\
\cline { 2 - 3 } & First injection & Reinjection \\
\hline 0.18 & 30 & 20 \\
0.2 & 40 & 30 \\
0.25 & 50 & 30 \\
0.3 & 60 & 40 \\
0.35 & 70 & 40 \\
0.4 & 80 & 50 \\
0.5 & 100 & 70 \\
0.6 & 120 & 80 \\
0.7 & 140 & 90 \\
0.8 & 150 & 100 \\
0.9 & 170 & 110 \\
1 & 190 & 120 \\
1.1 & 210 & 130 \\
1.2 & 220 & 140 \\
1.3 & 240 & 160 \\
1.4 & 260 & 170 \\
1.5 & 280 & 190 \\
1.6 & 300 & 200
\end{tabular}

$B S A$, Body surface area. *The numeric value of a No. 2 roller pump flow (Figure 1, cardioplegia rotor) in milliliters per minute is equal to the numeric value of the cardioplegic solution syringe pump flow in milliliters per hour.

Results of clinical use of IWBC were compared with those of 950 patients operated on with normothermic bypass and cold blood cardioplegia (CBC). The composition of the $\mathrm{CBC}$ was one third of blood withdrawn from the oxygenator and two thirds of potassiumenriched crystalloid solution. The final potassium concentration was influenced by the kalemia of blood in the oxygenator, the final result being about $19 \mathrm{mEq} / \mathrm{L}$. The two components were mixed in a plastic bag and cooled in iced water. They were injected by simple gravity in small children; in older children, a positive pressure generated about the plastic bag was necessary. The initial injection was directly related to body surface area with the formula $500 \mathrm{~mL} / \mathrm{m}^{2}$. Half the initial dose was reinjected every 20 to 30 minutes. The cardioplegic solution was most often aspirated from the right atrium outside the bypass circuit. The volume of fluid loss was equivalent to the blood withdrawn from the oxygenator; that is, one third of the total volume of cardioplegic solution. In a $3-\mathrm{kg}$ baby, $35 \mathrm{~mL}$ of oxygenator blood was wasted during the initial injection, and in a $10-\mathrm{kg}$ child, $80 \mathrm{~mL}$.

During the whole study, the surgical, anesthetic, perfusionist, and intensive care staff remained the same. Normothermic perfusion was used in both groups. Ultrafiltration, during or after bypass, was never used.

The peroperative and postoperative inotropic support was identical during the "cold" and "warm" periods. A phosphodiesterase inhibitor, as proved by the PRIMACORP study, ${ }^{8}$ was used prophylactically in patients at risk of low-output syndrome.

Several parameters were used to compare retrospectively the results obtained with the two techniques of cardioplegia. 
TABLE 2. Comparison of the 4 groups of patients

\begin{tabular}{|c|c|c|c|c|c|}
\hline Diagnosis & No. of patients & Mean age & Mean weight $(\mathbf{k g})$ & Aortic clamping time (min) & Down syndrome (\%) \\
\hline VSD, CBC & 75 & $3 \pm 1 \mathrm{mo}$ & $4.5 \pm 0.9$ & $28 \pm 7$ & \\
\hline VSD, IWBC & 148 & $\begin{array}{c}3 \pm 1 \mathrm{mo} \\
\mathrm{NS}\end{array}$ & $\begin{array}{c}4.3 \pm 0.8 \\
\text { NS }\end{array}$ & $\begin{array}{c}26 \pm 8 \\
N S\end{array}$ & \\
\hline TOF, CBC & 76 & $5 \pm 2 \mathrm{mo}$ & $6.4 \pm 1.7$ & $53 \pm 16$ & \\
\hline TOF, IWBC & 109 & $\begin{array}{c}5 \pm 2 \text { mo } \\
\text { NS }\end{array}$ & $\begin{array}{c}6.5 \pm 2.2 \\
\text { NS }\end{array}$ & $\begin{array}{c}52 \pm 16 \\
\text { NS }\end{array}$ & \\
\hline CAVSD, CBC & 55 & $4 \pm 3 \mathrm{mo}$ & $4.6 \pm 0.9$ & $75 \pm 19$ & $58 \%$ \\
\hline CAVSD, IWBC & 53 & $\begin{array}{c}4 \pm 2 \text { mo } \\
\text { NS }\end{array}$ & $\begin{array}{c}4.5 \pm 1.1 \\
\text { NS }\end{array}$ & $\begin{array}{c}77 \pm 14 \\
\text { NS }\end{array}$ & $\begin{array}{l}54 \% \\
\text { NS }\end{array}$ \\
\hline TGA, CBC & 49 & $7 \pm 2$ days & $3.3 \pm 0.5$ & $92 \pm 11$ & \\
\hline TGA, IWBC & 54 & $\begin{array}{c}6 \pm 3 \text { days } \\
\text { NS }\end{array}$ & $\begin{array}{c}3 \pm 0.4 \\
\mathrm{NS}\end{array}$ & $\begin{array}{c}82 \pm 14 \\
N S\end{array}$ & \\
\hline
\end{tabular}

VSD, Ventricular septal defect; TOF, tetralogy of Fallot; CAVSD, complete atrioventricular septal defect; TGA, transposition of the great arteries; $C B C$, cold blood cardioplegia; $I W B C$, intermittent warm blood cardioplegia; NS, nonsignificant.

- Hydric balance of the cardioplegic solution.

- Spontaneous resumption of electrical activity after release of the aortic crossclamp.

- Time of ventilatory support, level of troponin I 12 hours after aortic crossclamping, and length of intensive care unit (ICU) stay were analyzed in 4 selected patient groups of comparable age and weight (Table 2): in the IWBC group, ventricular septal defect less than 6 months old, 148 patients; tetralogy of Fallot less than 1 year old, 109 patients; atrioventricular septal defect less than 6 months old, 53 patients; and transposition of the great arteries in the neonatal period, 54 patients. In the CBC group numbers were respectively 75 ventricular septal defect, 76 tetralogy of Fallot, 55 atrioventricular septal defect, and 49 transposition of the great arteries.

- Length of stay in the ICU.

- Statistical analysis was performed by the Student $t$ test for comparison of means $\pm \mathrm{SD}$ and $\chi^{2}$ test for comparison of percentages.

\section{Results}

Since April 2001, 1400 patients were operated on with IWBC during aortic crossclamping. During this period, only neonates with infradiaphragmatic total anomalous pulmonary venous connection were treated with deep hypothermic circulatory arrest, and they are not included in this study.

In the IWBC group, the total volume of infused cardioplegic solution ranged from 3 to $6 \mathrm{~mL}$ in neonates to 50 $\mathrm{mL}$ in grown-up children of adult size. The cardioplegic solution represented the only addition in volume to the pump prime, as the sanguineous component of this solution was constituted by blood diverted from the bypass circuit and returned to it.

In patients with $\mathrm{CBC}$, hydric balance was variable: When the cardioplegic solution was discarded from the operating field, blood was lost from the bypass circuit (the total amount lost was related to the number of cardioplegic infusions); when the cardioplegic solution was inadvertently recuperated in the bypass circuit, dilution of the prime ensued.

Results with IWBC, compared with those with CBC, are depicted in Table 3. The proportion of spontaneous resumption of sinus rhythm after aortic unclamping is significantly better in IWBC patients. The delay between aortic clamp removal and resumption of sinus rhythm is short, electrical activity appears most often during deairing procedures, and sinus rhythm resumes within a few minutes.

The comparison was extended to selected diagnostic groups (Table 3) by evaluating the need for mechanical ventilation, the rise in troponin I level, and the length of ICU stay. Nonsurvivors and patients with extracardiac reasons for prolonged ventilation were excluded from this analysis (Table 4). Causes of death were sepsis (4 patients), hemorrhage (3 patients), or incorrect surgical cure: aortic insufficiency after arterial switch operation (1 patient) or massive mitral regurgitation after atrioventricular septal defect repair (2 patients). Extracardiac reasons for mechanical ventilation are severe pneumonia or respiratory syncytial virus infection with airway hypereactivity (4 patients), diaphragmatic paralysis (2 patients), or severe tracheal or subglottic stenosis confirmed by endoscopic examination (3 patients). Average duration of mechanical ventilation was consistently lower within the 4 diagnostic groups in patients operated on with the aid of IWBC. Troponin modification was also consistently lower and length of ICU stay was lower in patients with complete atrioventricular septal defect and transposition of the great arteries.

Patients with IWBC generally had better hemodynamic performance. In turn, this feature affected the duration of 
TABLE 3. Results

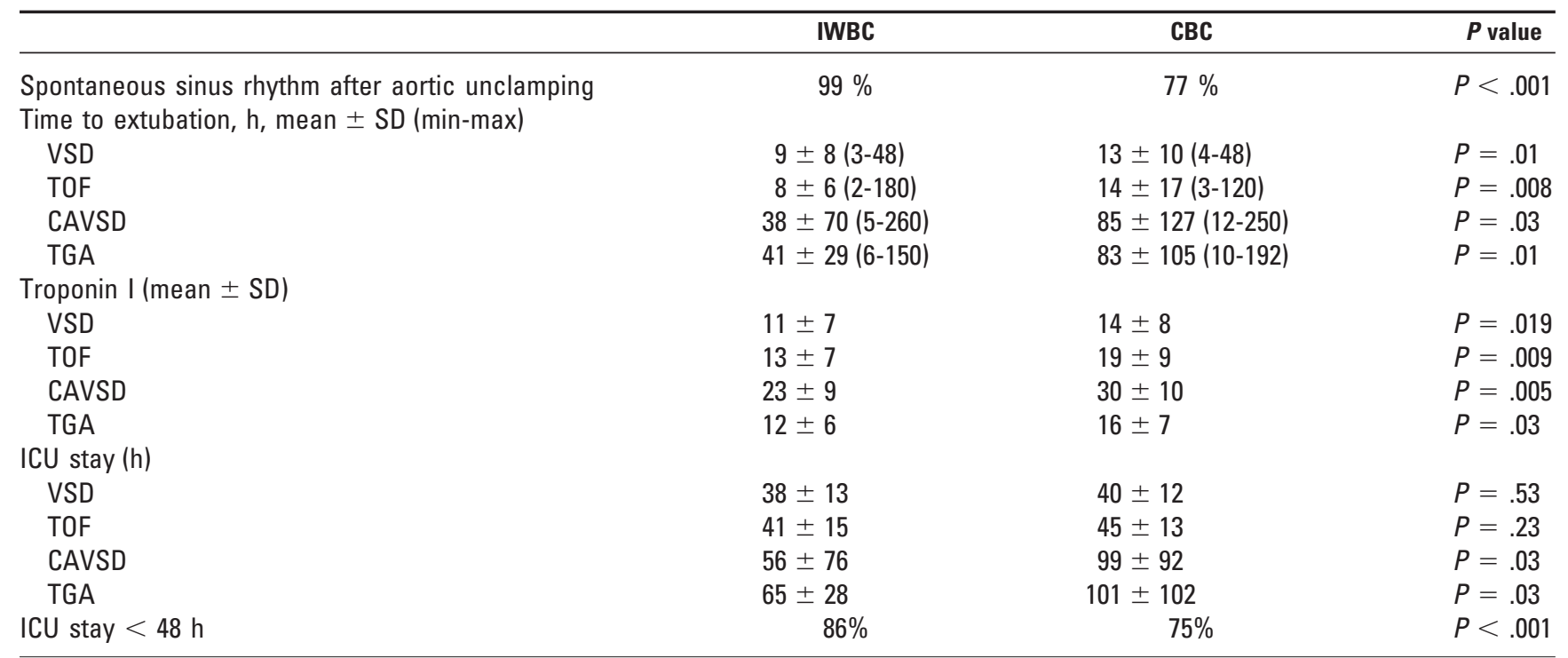

IWBC, Intermittent warm blood cardioplegia; CBC, cold blood cardioplegia; VSD, ventricular septal defect; TOF, tetralogy of Fallot; CAVSD, complete atrioventricular septal defect; TGA, transposition of the great arteries; ICU, intensive care unit.

ICU stay, which was significantly shorter for the whole IWBC group than for the CBC group $(P<.001)$.

\section{Discussion}

To our knowledge, this is the first report indicating that myocardial protection with IWBC in pediatric cardiac surgery is safe and effective.

Continuous warm blood cardioplegia seems unrealistic in pediatric surgery and is probably impossible in the repair of some cardiac defects. Since efficiency and safety of IWBC have been demonstrated in adults, ${ }^{4-6}$ its application may be considered for pediatric surgery.

A warm solution is as efficient as a cold one in inducing hyperkalemic cardiac arrest. An advantage of IWBC is its absence of influence on hydric balance, the fluid volume added to the bypass circuit being negligible. On the contrary, a cold cardioplegic solution is composed of crystalloid mixed with blood from the oxygenator. The final hematocrit of the solution is around $10 \%$, in the range described as beneficial by experimental work. ${ }^{9}$ The cardioplegic solution is either discharged outside with blood loss or aspirated in the cardiotomy reservoir, with increased prime dilution. The prime loss for each cardioplegic injection may require the addition of extra fluid in the bypass circuit, increasing blood consumption.

The adjunction of a cell salvage device is inefficient to counteract this side effect. The volume of each cardioplegic infusion is small and the delay to obtain the washed concentrated blood is too long to avoid extra fluid addition. The benefit of ultrafiltration is also questionable because of the extra volume needed to prime the hemofilter circuit. Our rationale is to improve tolerance to cardiopulmonary bypass by decreasing prime volume solution. We use a prime (including priming of the cardioplegic circuit) of $140 \mathrm{~mL}$ for infants up to $5.5 \mathrm{~kg}$ and of $170 \mathrm{~mL}$ for patients weighing between 5.6 and $13 \mathrm{~kg}$. To achieve this small volume, we eliminated every component that is not absolutely mandatory, such as the ultrafiltration circuit. During hypothermic perfusion, hemodilution is frequently used; on the contrary, normothermic perfusion is commonly performed with normal hematocrit values, so there is hardly any need to hemoconcentrate the patient. In any case, the absence of

TABLE 4. Patients excluded from the study

\begin{tabular}{lcccccccc}
\hline CHD & VSD CBC & VSD IWBC & TOF CBC & TOF IWBC & AVSD CBC & AVSD IWBC & TGA CBC & TGA IWBC \\
\hline Died $\%$ & $0[0]$ & $1(\mathrm{~S})[0,6]$ & $1(\mathrm{~S}) 1$ & $0[0]$ & $1(\mathrm{ISC})[2]$ & $1(\mathrm{ISC})[2]$ & $3(\mathrm{H}$, ISC, S) [6] & $3(\mathrm{H}, \mathrm{H}, \mathrm{S})[5]$ \\
ECPMV & 0 & 0 & $2(\mathrm{DP}, \mathrm{P})$ & $3(\mathrm{P}, \mathrm{P}, \mathrm{AS})$ & $1(\mathrm{AS})$ & $2(\mathrm{P}, \mathrm{AS})$ & $1(\mathrm{DP})$ & 0 \\
\hline
\end{tabular}

Causes of death: $S$, sepsis; ISC, incorrect surgical cure; $H$, hemorrhage; ECPMV, Extracardiac reason for prolonged mechanical ventilation; $D P$, diaphragmatic paralysis, $P$, pneumoniae; $A S$, airway stenosis. $C H D$, Congenital heart defect; $V S D$, ventricular septal defect; TOF, tetralogy of Fallot; $A V S D$, atrioventricular septal defect; TGA, transposition of the great arteries; $C B C$, cold blood cardioplegia; IWBC, intermittent warm blood cardioplegia. 
side effect on fluid balance of IWBC allows a simpler bypass procedure.

The main limitation of this study is its retrospective nature. However, we believe that there are some arguments to its validity:

- The number of patients studied is large (1400) in a 5 -year period. During this period there were no major changes in the staff or in the management of patients.

- The resumption of sinus rhythm after aortic unclamping in nearly all patients has been described in adult patients as well, operated on with warm cardioplegia. ${ }^{4-10}$ The myocardial protection is critical in neonates, deeply cyanotic infants, ${ }^{11}$ and those with prolonged aortic crossclamping times. In our analysis, we have chosen 4 groups of patients who may represent increasing need of myocardial protection. These groups were composed by patients as similar as possible. Patients with associated malformations were excluded. Age limits were adapted to avoid clinical dissimilarities.

Time to extubation is not a direct effect of myocardial protection but is used as an index of quality of cardioplegia. ${ }^{11-13}$ Spontaneous breathing is an important stage in the postoperative period, which implies adequate hemodynamic and gas exchange. We have excluded from the analysis patients with an extracardiac reason for prolonged ventilation as well as nonsurvivors. The number of excluded patients is low and similar in each group.

Mortality is equivalent with the 2 techniques of cardioplegia; death followed imperfect surgical repair (3 cases), hemorrhage (3 cases ), and sepsis (4 cases). Similar events are most unlikely related to cardioplegia.

Furthermore, the inclusion of time to ventilation of nonsurviving patients is open to criticism inasmuch as $50 \%$ of patients died within 12 hours.

The modification of troponin level is used to evaluate the quality of myocardial protection, but it may also be influenced by the type of cardiac defect. ${ }^{12-16}$ The rise in troponin level is more important in pediatric than in adult patients, and the widest variations are described after surgery for complete atrioventricular septal defect, tetralogy of Fallot, and homograft or xenograft implantation. ${ }^{17}$ For this reason, consensus is lacking on the value of the median or peak level after pediatric surgery: around 4 to $7 \mathrm{ng} / \mathrm{mL}$ after arterial switch ${ }^{18}$ or $25 \mathrm{ng} / \mathrm{mL}$ as a cutoff point for the definition of a high- and a low-risk group. ${ }^{19}$ Our data are in concordance with the literature: the higher levels of postoperative troponin I are found in complete atrioventricular septal defect and tetralogy of Fallot. Troponin increase is significantly lower in the 4 groups treated with IWBC than in those treated with CBC. Time to extubation is lower in patients with ventricular septal defect and tetralogy of Fal- lot. The difference is significant but too short to modify length of ICU stay. On the contrary, time to extubation and ICU stay are significantly shorter for patients with complete atrioventricular septal defect and those with transposition of the great arteries.

ICU stay is shorter with IWBC than with CBC. In our practice, IWBC is associated with improved hemodynamic stability, allowing early extubation in the majority of cases. Resumption of feeding commonly starts in the first 12 hours after the operation, and duration of inotropic support rarely exceeds 48 hours.

The percentage of patients who require postoperative inotropic support is also considered as a relevant factor in evaluating the efficacy of myocardial protection..$^{11,17,20}$ These data were not analyzed in this study. Enoximone was used prophylactically in neonates and infants at risk of low cardiac output syndrome along with the PRIMACORP study, which showed a $64 \%$ relative risk reduction in the development of low cardiac output syndrome with the prophylactic use of a similar drug, milrinone. ${ }^{8}$ An identical prophylactic treatment has been used in the 2 groups of patients compared in this study; that is, before weaning from bypass, all the patients within the 4 groups studied received a loading dose of enoximone, $1 \mathrm{mg} / \mathrm{kg}$ in 15 minutes followed by a continuous infusion of $10 \mu \mathrm{g} \cdot \mathrm{kg}^{-1} \cdot \mathrm{min}^{-1}$.

\section{Conclusions}

Quality of cardiac surgery outcome cannot be attributed to any single element in the procedure. This analysis of a large group of patients treated over a 5-year period allowed us to show that pediatric cardiac surgery with normothermic myocardial protection is a valid alternative to cold cardioplegia. This preliminary work should be validated by prospective studies.

We thank Duccio Di Carlo, MD, for his critical review of this work and Françoise Zerah Lancner, MD, for statistical expertise.

\section{References}

1. Lichtenstein SV, El-Dalati H, Panos A, Slutsky AS. Long cross-clamp time with warm heart surgery. Lancet. 1989;1:1443.

2. Mauney MC, Kron IL. The physiologic basis of warm cardioplegia. Ann Thorac Surg. 1995;60: 19-23.

3. Martin TD, Craver JM, Gott JP, Weintraub WS, Ramsay J, Mora CT, et al. Prospective, randomized trial of retrograde warm blood cardioplegia: myocardial benefit and neurological threat. Ann Thorac Surg. 1994;57:298-304.

4. Jacquet LM, Noirhomme PH, Van Dyck MJ, El Khoury GA, Matta AJ, Goennen MJ, et al. Randomized trial of intermittent warm blood versus cold crystalloid cardioplegia. Ann Thorac Surg. 1999;67:471-7.

5. Mezzeti A, Calafiore A, Lapenna D, Deslauriers R, Tian G, Salerno $\mathrm{TA}$, et al. Intermittent antegrade warm cardioplegia reduces oxidative stress and improves metabolism of the ischemic reperfused human myocardium. J Thorac Cardiovasc Surg. 1995;109:787-95.

6. Caputo M, Ascione R, Angelini GD, Suleiman MS, Bryan AJ. The end of the cold era: from intermittent cold to intermittent warm blood cardioplegia. Eur J Cardiothorac Surg. 1998;14:467-75.

7. Doenst T, Schlensak C, Beyersdorf F. Cardioplegia in pediatric cardiac surgery: do we believe in magic ? Ann Thorac Surg. 2003;75:1668-77. 
8. Hoffman TM, Wernovsky G, Atz AM, Kulik TJ, Nelson DP, Chang $\mathrm{AC}$, et al. Efficacy and safety of milrinone in preventing low cardiac output syndrome in infants and children after corrective surgery for congenital heart disease. Circulation. 2003;107:996-1002.

9. Chaudhry MA, Belcher PR, Day SP, Muriithi EW, Wheatley DJ. Erythrocyte-containing versus crystalloid cardioplegia in the rat: effects on myocardial capillaries. Ann Thorac Surg. 2003;75:890-8.

10. Lessana A, Romano M, Singh AI, Yu HQ, Palsky E, Le Houerou D, et al. Heart surgery in normothermia and aerobiosis: apropos of 530 patients. Arch Mal Coeur Vaiss. 1992;85:1545-50.

11. Imura H, Caputo M, Parry A, Pawade A, Angelini GD, Suleiman MS. Age-dependent and hypoxia-related differences in myocardial protection during pediatric open heart surgery. Circulation. 2001; 103:1551-6.

12. Caputo M, Modi P, Imura H, Pawade A, Parry AJ, Suleiman MS, et al. Cold blood versus cold crystalloid cardioplegia for repair of ventricular septal defects in pediatric heart surgery: a randomized controlled trial. Ann Thorac Surg. 2002;74:530-5.

13. Vaughn CC, Opie JC, Florendo FT, Lowell PA, Austin J. Warm blood cardioplegia. Ann Thorac Surg. 1993;55:1227-32.

14. Falcoz PE, Kaili D, Chocron S, Toubin G, Puyraveau M, Viel JF, et al. Warm and tepid cardioplegia: do they provide equal myocardial protection? Ann Thorac Surg. 2002;74:2156-60.
15. Modi P, Suleiman MS, Reeves B, Pawade A, Parry AJ, Angelini GD, et al. Myocardial metabolic changes during pediatric cardiac surgery: a randomized study of three cardioplegic techniques. J Thorac Cardiovasc Surg. 2004;128:67-75.

16. Gianessi D, Caselli C, Vitale RL, Crucean A, Murzi B, Ry SD, et al. A possible cardioprotective effect of heat shock proteins during cardiac surgery in pediatric patients. Pharmacol Res. 2003;48:51929.

17. Siaplaouras J, Thul J, Will JC, Bauer J, Kreuder J, Valeske K, et al. Cardiac troponin I after heart surgery: corrective operation in infancy and childhood. Z Kardiol. 2001;90:408-13.

18. Imura H, Modi P, Pawade A, Parry AJ, Suleiman MS, Angelini GD, et al. Cardiac troponin I in neonates undergoing the arterial switch operation. Ann Thorac Surg. 2002;74:1998-2002.

19. Immer FF, Stocker F, Seiler AM, Pfammatter JP, Bachmann D, Printzen G, et al. Troponin-I for prediction of early postoperative course after pediatric cardiac surgery. J Am Coll Cardiol. 1999;33: 1719-23.

20. Young JN, Choy IO, Silva NK, Obayashi DY, Barkan HE. Antegrade cold blood cardioplegia is not demonstrably advantageous over cold crystalloid cardioplegia in surgery for congenital heart disease. J Thorac Cardiovasc Surg. 1977;114:1002-9.

\section{Online - www.aats.org}

Now you can get The Journal of Thoracic and Cardiovascular Surgery online. The Journal online brings you faster delivery time, easy searching of current and back issues, links to PubMed, AATS, WTSA, and other important sites, and more. Visit the Journal online today.

\section{Receive tables of contents by e-mail}

To receive the tables of contents by e-mail, sign up through our Web site at http://journals.elsevierhealth.com/periodicals/ymtc

Choose E-mail Notification

Simply type your e-mail address in the box and click the Subscribe button. You will receive an e-mail to confirm that you have been added to the mailing list.

Note that TOC e-mails will be sent out when a new issue is posted to the Web site. 